\title{
iSE HACE CAMINO AL EDUCAR! \\ Propuestas educativas al Perú del Bicentenario a la luz de la historia
}

\author{
PATHS ARE CREATED BY TEACHING! \\ Educational proposals to the Bicentennial Peru in light of the history
}

José Antonio Benito ${ }^{1}$

\begin{abstract}
Caminante, son tus huellas
el Perú y nada más; caminante, sí hay camino, se hace camino al educar

Wander, your footprints are

Peru, and nothing else; wander, ther is a path

By teaching, a path is created
\end{abstract}

\section{RESUMEN}

Más allá del recuerdo de la gesta política libertadora de 1821 del Perú independiente, se destaca una de las claves para entender la trayectoria histórica del Perú: su rico patrimonio educativo y cultural logrado a base de caminar, tanto en sus peregrinaciones religiosas como en sus realizaciones educativas. Por tanto, el mejor modo de celebrar el bicentenario será conociendo integralmente su legado cultural y comprometiéndose con una educación integral e inclusiva, de todo hombre y de todos los hombres del Perú.

\section{Palabras clave}

Perú, camino, educación, patrimonio, bicentenario, globalización.

\section{ABSTRACT}

Beyond the memory of independent Peru's liberation war in 1821, we emphasize one of the keys to understand its historical journey: its rich educational and cultural heritage made from walking, both in its religious pilgrimage and in its educational accomplishments. Therefore, the best way to commemorate the bicentennial will be to know in a thorough way its cultural legacy and to commit ourselves to an inclusive and complrehensive education for all Peruvians.

\section{Keywords}

Peru, path, education, heritage, bicentennial, globalizatión

Historiador, Director del CEPAC, Universidad Católica Sedes Sapientiae. 


\section{INTRODUCCIÓN}

Después de compartir 20 años de mi vida en el Perú, estudiando su historia, tras miles de horas hurgando documentos, $y$, sobre todo, conmovido por las miles de peripecias vividas en esta patria milenaria y pluricultural, quiero mostrar:

1. Que el Perú se ha forjado caminando, anudando lazos, tejiendo sueños.

2. Que su riqueza natural y cultural, convertida en leyenda en tiempos del virreinato, seguirá ejerciendo una fascinación creciente en tiempos de globalización con tal de que permanezca fiel a su peruanidad, su síntesis viviente, que incluye todas las sangres y culturas.

3. Que la clave de su identidad y poderosa personalidad estriba en la pasión del Perú por educar, oficio de "alto riesgo pero hermoso" (L. J. Cisneros).

4. Que el mayor tesoro del Perú de ayer, hoy, siempre, lo hallamos en sus protagonistas educadores que dieron lo mejor de sí por el desarrollo integral y solidario de su patria. Fueron ayer, son ahora y pueden ser en el 2021 y más allá del tiempo y sus fronteras imaestros!

Ellos convirtieron su prosa cotidiana en un poema heroico.

Yo también quiero aportar mi granito de arena en la tarea y adelanto, con palabras prestadas del poeta Marco Martos y que me sorprendieron gratamente en $\mathrm{mi}$ visita al Museo Nacional de Pueblo Libre, mi convicción:

No es este tu país porque conozcas sus linderos, ni por el idioma común, ni por los nombres de los muertos.

Es este tu país, porque si tuvieras que hacerlo, lo elegirías de nuevo para construir aquí todos tus sueños

\section{EL PERÚ, UN CAMINO}

Si Antonio Machado cantó de una vez por todas que "se hace camino al andar", también podemos glosar -en el Perú, aquí y ahora- que se hace camino al educar.

Si Goethe afirmó que Europa se hizo a sí misma peregrinando, también se ha escrito -y con mucho acierto- que el Perú forjó su destino en el paso a paso, en la itinerancia de un largo camino.

Antonello Gerbi, en su bella obra Caminos del Perú, se detiene en marcar la diferencia, en acreditar su denominación de "origen" y "destino":

El Perú es un camino. Otros países pueden resumirse en un símbolo geográfico. Egipto es un valle, el Brasil una selva, la Argentina una pampa, Siberia un estepa, Inglaterra una isla, Panamá un istmo cortado y Suiza un puñado de montañas consteladas de hoteles. El Perú es un camino. (1994, p. 7)

Y este camino nos sirve y nos enseña, nos estimula y nos alimenta. El vate José Santos Chocano lo canta desde la entraña de su alma:

Indio que a pie vienes de lejos...

Ahí no más encuentras siempre cuanto deseas encontrar. Y, sí se siente, en lo profundo de ese desprecio con que das, sabia ironía a las distancias una emoción de eternidad. (Chocano)

El historiador Luis Miguel Glave señala en este sentido que "en un territorio tan difícil, agreste $e$ inmenso, los diversos pueblos que han definido la existencia de la nación peruana, lo han hecho caminando" (1999, p. 64), en permanente itinerancia, pero fieles a sí mismos, bebiendo de su propio pozo, abiertos a la globalidad. Víctor Andrés Belaunde acuñó el término de "peruanidad": La peruanidad es un hecho, una vivencia, ella no permite desnaturalizaciones o mutilaciones. Nosotros proclamamos muy alto nuestro concepto de 
la peruanidad, una, indivisible; la peruanidad integral. Síntesis viviente de la tierra y de la raza aborigen, y de la raza y la cultura hispano-católica, la peruanidad exhibe con orgullo sus dos herencias y no acepta que se las disminuya ni se las tergiverse. La gloriosa sombra del incario se prolonga en el virreinato y es nuestra misión perpetuarla en la república". (1993, p.185).

Los caminos andinos, las apachetas montículos de pequeñas piedras- en cerros y nevados, fueron transitados por hombres y mujeres, que portaban consigo "bienes, ideas, miedos y esperanzas" (Glave, 1999, p. 65). El P. José de Acosta, S. J. escribirá que los indios emplean mil maneras para cruzar los ríos. A través de puentes con estructuras de piedra, de madera, puentes colgantes con estructuras de fibras; por oroya que era una canasta suspendida de un cable conectado a ambas márgenes de un río, al parecer era el método más aterrador y puentes flotantes: puentes sobre pontones de juncos flotantes (1954 [1590], libro sexto, cap. XIV).

John Hyslop se ha adentrado en los estudios para reconstruir esta trama vial inkaicaQhapaqñan de unos $23.000 \mathrm{kms}$ sobre uno de los terrenos más abruptos y que sirvió para el transporte, las comunicaciones y la administración del Estado más importante de la historia prehispánica².

Los centros organizadores del espacio andino eran símbolos sagrados, centros de atracción y concentración, donde se rendía culto a la divinidad y se aceptaba la autoridad de los que consideraban sus representantes en la tierra. Centros ceremoniales como Toro Muerto, Chavín o Pachacamac, nevados como el Ampato o Sara Sara, recibían devotos peregrinos que acudían a pedir un favor o a agradecer un don.

Los españoles aportaron su larga tradición peregrina y recrearon su identidad en lugares santos, normalmente frecuentados por la población andina. Los naturales acogieron las formas hispanas y las asumieron recreando sus cultos y costumbres ancestrales en devociones aceptables para el mundo cristiano.

Sorprende, sin embargo, que en el pueblo sencillo, de a pie, anidase una conciencia universal cosmopolita que le llevase a pensar como algo normal el visitar lugares tan distintos y distantes como Copacabana de Bolivia, Guadalupe de México, en las Indias o Compostela y Roma en Europa, sin perder de vista Jerusalén en Asia. Es el caso de Pedro de Aragón que en 1660 "pide licencia para ir en romería a Nuestra Señora de Copacabana y Santiago de Galicia reinos de España en hábito de peregrino". A través de los testigos que presenta podemos conocer los motivos estrictamente religiosos que le impulsan a peregrinar. El hecho de que enfaticen que no lleva otros motivos, puede representar que sí que había peregrinos "fingidos". Nuestro peregrino Pedro de Aragón da fe

que estando muy enfermo en la cama de dicha grave enfermedad de que estuve en riesgo de morir hice voto y promesa de ir en romería a visitar los templos de Nuestra Señora de Copacabana y en las provincias de arriba y de allí a la iglesia de Santiago del reino de Galicia en los reinos de España y para poder cumplir el dicho voto y promesa... pido y suplico se sirva de concederme licencia para ir en hábito de peregrino a la dicha promesa y romería pidiendo limosna en las partes que tuviere necesidad de ella por ser persona pobre y siendo necesario ofrezco información del dicho voto y promesa para que no se me impida por ninguna persona. Fdo. Pedro de Aragón (AAL, Papeles Importantes, V 20)

El 20 de marzo 1660 presentó por testigo al alférez Lorenzo de los Reyes quien dijo que

Hyslop, John (1992) Qhapaqñan (El sistema vial inkaico) Instituto Andino de Estudios Arqueológicos, Petróleos del Perú (Traductor Eduardo Arias), Lima. Son numerosos los organismos como AECI que van asociándose para reconstruir este auténtico lazo de integración que fue el camino inca. 
lo conocía desde hacía diez meses a esta parte poco más o menos de vista, trato y comunicación y por haber a tiempo de 7 meses poco más o menos que estando este testigo enfermo en el hospital de San Andrés lo estaba también el dicho Pedro de Aragón de dicha postema en la corva de la pierna derecha de que estuvo muy a riesgo de morir sacramentado y oleado y por esta razón hizo voto y promesa de que dándole Dios salud iría en romería a visitar la iglesia de Nuestra Señora del convento de Copacabana en las provincias de arriba y después pasaría en la misma romería a los reinos de España a visitar la iglesia de Santiago en el reino de Galicia de la ciudad de Compostela $y$ este testigo se halló presente al dicho voto y promesa" dejando claro que el fin no "es a fin de ir vagando sino solo por hacer lo que es obligado.(AAL, Papeles Importantes)

Hay expedientes de peregrinos residentes en Lima como el griego Jorge Condoleo quien pide licencia en 1611 para ir como peregrino a Jerusalén (AAL, 1611, leg. III, exp. 12 ). De igual modo, nos encontramos con limeños deseosos de peregrinar a Tierra Santa como Onofre, "gran pecador" (AAL, leg. III, exp. 14) en 1620, Diego Mateo Jiménez en 1621 (AAL, leg. III, exp. 20) y Rodrigo Solano, quien en 1635 "pide licencia para ir a visitar las santas casas de Guadalupe y Copacabana en hábito de romero" (AAL, leg. III, exp. 21).

Desde la costa, sierra, selva podemos corear con Walt Whitman en "Canto del Camino abierto" "Aspiro grandes bocanadas de espacio; El Este y el Oeste son míos y el Norte y el Sur míos son... El Universo es un camino -innumerables caminos- caminos para almas trashumantes". (Whitman)

La geografía, la historia y la intrahistoria ${ }^{3}$ del Perú nos brindan caminos como lazos que tejen y forjan una vocación, una misión: estar en movimiento pero sin perder la calma, sin prisa pero sin pausa, sin cansarse nunca de estar comenzando siempre. Cuando parece que se ha llegado a la meta, entonces se puede dar un paso más. En la tierra, en el agua, en el aire: "iArriba, siempre arriba, hasta las estrellas!" como exclamó el héroe aviador trasalpino Jorge Chávez.

Podría añadir otro aporte más, el religioso. La palabra "sínodo" significa camino y en el Perú se han celebrado hasta la fecha diecinueve sínodos, trece de ellos por el gran itinerante y misionero, padre de la patria peruana, Santo Toribio Alfonso de Mogrovejo. Este mismo año, la arquidiócesis de Lima vive el XX Sínodo de su historia $y$ convoca a sus fieles ser protagonistas, caminando unidos, en gozosa misión, como alentó la Conferencia de Aparecida, como propicia el Papa Francisco - cual nuevo cruzado- al grito de iEvangelii gaudium!: caminen y evangelicen con gozo.

\section{EL PERÚ, UN TESORO}

Pero el Perú, como Iberoamérica, más que continente es contenido. El camino señalado no es solo un lugar de paso, es también un tesoro acumulado, un legado que se hereda agradecido, una tradición viva que se transmite responsablemente y una meta esperanzada que se construye. Cuando hablamos de patrimonio nos referimos a la herencia de bienes materiales e inmateriales que nuestros padres $y$ antepasados nos han dejado a lo largo de la historia. Se trata de bienes que nos ayudan a forjarnos una identidad como nación y que nos permiten saber quiénes somos y de dónde venimos, logrando así un mejor desarrollo como personas dentro de la sociedad

Entre los millones de viajeros llegados al Perú profundo, ombligo del mundo, Cuzco, uno de ellos, el Papa Juan Pablo II exclamó emocionado el 3 de febrero de 1985:

Esta gigantesca fortaleza de Sacsayhuamán ante la que nos encontramos, es símbolo de colaboración

\footnotetext{
Vocablo usado habitualmente por Miguel de Unamuno para referirse a lo más profundo y vital de la historia.
} 
mutua. No pudo ser edificada sin la labor conjunta de vuestros antecesores, sin la acoplada unión de tantas piedras. Tampoco podrá construirse una Patria grande sin fraternidad y ayuda mutua, sin justicia entre el poblador del campo y el habitante de la ciudad, sin equilibrio entre el crecimiento técnico e industrial, sin el cuidado esmerado por los problemas agrícolas. Es un terreno que reclama la obligada atención de las autoridades públicas, con medidas adecuadas y urgentes que incluyan, cuando sea necesario, las debidas reformas en la propiedad y su explotación. Es un problema de justicia $y$ humanidad (1985).

Parece un eco del cronista, Francisco Antonio de Montalvo, quien tres siglos antes, en 1683, escribía en su obra El Sol del Nuevo Mundo:

Es tan afortunado por naturaleza este Nuevo Mundo que no tiene cosa mala, porque su cielo es benévolo, su aire apacible, su agua saludable y su tierra fértil... La tierra del Perú es la más rica y feliz que conoce el mundo. (libro V, cap. 3)

A tanto llegó el pasmo, la admiración, por el Perú, que uno de ellos, Antonio de León Pinelo en su obra El Paraíso en el Nuevo Mundo llega a ubicar el Paraíso en nuestra tierra, en las inmediaciones de Iquitos, en las márgenes del río Marañón (1943 [1656]), Ya no nos extraña que llegase a acuñarse en el mundo la expresión "Valer un Perú" como "Ser de mucho precio o estimación". Nos recuerda que hubo un tiempo en que Perú era sinónimo de "estima" "valor". Y así lo plasmó el poeta Chocano en versos inmortales:

iVale un Perú! - y el oro corrió como una onda. iVale un Perú! - y las naves lleváronse el metal... Pero quedó esa frase magnífica y redonda, Como una resonante medalla colonial. (Chocano)
Parecida expresión constatamos en la ilustrada Francia, al final de la inmortal obra de Los miserables de Víctor Hugo, el malo de la historia, el tabernero Thénardier, parte a la América del Sur "du coté" de Panamá, exótico lugar donde los naturales tienden a vivir apelotonados en larguísimas viviendas y que aún hoy, en Francia, ha quedado la costumbre del siglo XVIII de exclamar c'est n'est pas le Pérou! (iEsto no es el Perú!) para decir que algo no es tan opulento como las riquezas milyunanochescas de ese continente $e^{4}$. Justo ha sido el motivo del reciente congreso internacional titulado "Riche comme le Pérou. Miradas recíprocas: Perú y Francia (1713-1959) Viajeros, escritores y analistas" celebrado en Lima del 4 al 6 de septiembre del 2014 y en el que he podido participar.

Desde 1534 Francia supo del Perú y de sus tesoros convertidos en botín por los conquistadores españoles. Las cartas y crónicas que dieron cuenta de los sucesos que protagonizaron Pizarro y Atahualpa no tardaron en ser vertidas al francés, lo mismo que a otras lenguas.

"Riche comme le Pérou" o "Ce n'est pas le Pérou" se escuchó decir durante mucho tiempo como expresión de ponderación extrema. Pero no solo la riqueza natural atrajo las miradas francesas sobre el imperio inca y el vastísimo virreinato sudamericano, también su geografía, su historia y sus pueblos se hicieron materias de estudio y reflexión, inclusive desde el siglo XVII. A partir del XVIII -Amadeo Frezier arribó al Callao en 1713- se multiplicaron los enfoques, las expediciones, los análisis, hasta aquellos realizados sin contacto físico con el medio peruano, fruto antes de la imaginación que de la experiencia.

Con toda razón, el Congreso Constituyente del Perú, presidido por Gregorio Paredes, dicta la Ley del 25 de febrero de 1825, en la que establece el nuevo escudo de armas del Perú de la siguiente manera:

\footnotetext{
Recordado por M. Vargas Llosa en su discurso en la PUCP al recibir la condecoración como doctor honoris causa http:// www.pucp.edu.pe/puntoedu/images/documentos/institucionales/sueno-realidad.pdf
} 
Considerando que es necesario fijar el escudo de armas que distinga a la Nación, se decreta: Las armas de la Nación Peruana constarán de un escudo dividido en tres campos: uno azul celeste a la derecha, que llevará un vicuña mirando al interior; otro blanco a la izquierda, donde se colocará el árbol de la Quinua,(sic) y otro inferior y más pequeño, en que se verá una Cornucopia derramando monedas, significándose con estos símbolos, las preciosidades del Perú en los tres reinos naturales. El Escudo tendrá por timbre una corona cívica, vista de plano, $e$ irá acompañado en cada lado de una bandera y un estandarte de los colores nacionales (Gaceta del Gobierno, 10 de marzo de 1825).

Tales riquezas se expresan en una identidad cultural que aglutina y hermana como si se tratase de un paradigmático microcosmos. Bellamente lo expresó el laureado premio Nobel de literatura, Mario Vargas Llosa, en Estocolmo, el 10 de diciembre del 2010, al pronunciar su discurso "Elogio de la lectura y la ficción" con motivo de la recepción del galardón:

Allí aprendí que el Perú era parte de una vasta comunidad a la que hermanaban la historia, la geografía, la problemática social y política, una cierta manera de ser y la sabrosa lengua en que hablaba y escribía [...] Y un compatriota mío, José María Arguedas, llamó al Perú el país de "todas las sangres". No creo que haya fórmula que lo defina mejor. Eso somos y eso llevamos dentro todos los peruanos, nos guste o no: una suma de tradiciones, razas, creencias y culturas procedentes de los cuatro puntos cardinales. A mí me enorgullece sentirme heredero de las culturas prehispánicas que fabricaron los tejidos y mantos de plumas de Nazca y Paracas y los ceramios mochicas o incas que se exhiben en los mejores museos del mundo, de los constructores de Machu Picchu, el Gran Chimú, Chan Chan, Kuelap, Sipán, las huacas de La Bruja y del Sol y de la Luna, y de los españoles que, con sus alforjas, espadas y caballos, trajeron al Perú a Grecia, Roma, la tradición judeo-cristiana, el Renacimiento, Cervantes, Quevedo y Góngora, y la lengua recia de Castilla que los Andes dulcificaron. $Y$ de que con España llegara también el África con su reciedumbre, su música y su efervescente imaginación a enriquecer la heterogeneidad peruana. Si escarbamos un poco descubrimos que el Perú, como el Aleph de Borges, es en pequeño formato, el mundo entero. iQué extraordinario privilegio el de un país que no tiene una identidad porque las tiene todas! (2010)

\section{EL PERÚ, UN RIESGO GOZOSO}

Si concebimos la educación como una "operación de alto riesgo", a la vez que "hermosa" ". Si aceptamos que el Perú se encuentra en este momento en "estado de misión educativa" frente a la dramática emergencia que sufre. $\mathrm{Si}$ apostamos por instituciones permanentes que forjen maestros de peruanidad, necesitamos con urgencia descubrirlas, conocerlas, difundirlas, apoyarlas, imitarlas.

Una buena iniciativa es la que nos brinda la Derrama Magisterial en sus quince volúmenes de la "Colección de Pensamiento Educativo Peruano" que, -como indica su prospecto-, busca contribuir al conocimiento de la evolución del pensamiento educativo peruano desde del siglo XV hasta la actualidad. Abarca desde las originales formas educativas desarrolladas en el período incaico hasta el siglo XX-XXI, época del Proyecto Educativo Nacional (PEN) y la revolución tecnológica, en el que parece culminar un largo proceso de ensayos y reformas educativas. Se pretende dar cuenta sobre cómo se ha pensado y

Término Acuñado por Luis Jaime Cisneros en la presentación de la revista "Riesgo de educar", 18 de julio de 2008, en la Universidad Católica Sedes Sapientiae. 
vivido la educación, y qué caminos se han seguido en este proceso articulado en tres grandes períodos:

En el primero predomina una instrucción para formar súbditos, en la época colonial; en el segundo, una educación para formar ciudadanos criollos en el siglo XIX, en una patria muy chica y condenada al fracaso. Por último, en el tercero, en pleno siglo XX, prospera una educación en la que se busca integrar la diversidad - de género, étnica y cultural - dentro de una sola colectividad con lugar para todos: culturas y personas diferentes que habitan el territorio peruano. (Derrama)

La primitiva educación formal — creada por el Inca Roca y difundida por Pachacutecfue diseñada exclusivamente para la élite real y los hijos de los curacas conquistados. Se les educaba para ser administradores y gobernantes, al tiempo que se les impartía una fuerte dosis de filosofía y moral, con altos contenidos de aritmética y astronomía necesarios para una organización económica basada en la agricultura. Los haravicus, que fueron los inventores de poemas; los huillachumo, eran transmisores del conocimiento del oficio divino. El aprendizaje del quechua fue obligatorio más por razones políticas que educativas.

Por su parte, la eeducación informal hace referencia al aprendizaje y transmisión de conocimientos que adquirió el hombre común que conformaba las comunidades $y$, específicamente, los ayllus dentro de la administración incaica. Dicha educación se caracterizaba por la transmisión de conocimientos dirigidos especialmente a la producción de bienes (Gonzalez, 2004, p. 94), para poder así satisfacer las necesidades no solamente de la comunidad propiamente dicha sino, las necesidades tributarias de la elite cuzqueña.

El hombre de ayllu se va educando progresivamente, esto significa que a muy temprana edad, va tomando responsabilidades y conocimientos, primero dentro de la familia y posteriormente dentro del ayllu. Esta educación se caracteriza porque el individuo hace suyo un conjunto de conocimientos y técnicas que le ayude no solamente a desenvolverse dentro de su sociedad sino también a transformar su entorno. Los conocimientos los va adquiriendo teniendo presente los diversos momentos importantes de su desarrollo como persona, nos referimos al ciclo vital de la vida (niñez, juventud, adultez y ancianidad).

La actividad académica del yachayhuasi, descansaba en la inter-relación de tres personajes que integraban la comunidad educativa: El primero era el amauta o "sabio prudente o Maestro, el yachacuc runa $\mathrm{u}$ "hombre sabio", discípulos o jóvenes alumnos que recibían las lecciones del amauta, y el haravicu o "poeta", quien cumplía la función de docente auxiliar, pues mediante sus canciones y versos, hacía que las lecciones del amauta sean repetidas y cantadas por los jóvenes con el único fin de facilitar el aprendizaje.

Entre los materiales didácticos cabe destacar el quipu, instrumento mnemotécnico utilizado para llevar la cuenta de los tributos, la estadística demográfica, el recuerdo de los hechos pasados, así como la razón de sus leyes y ordenanzas, ritos y ceremonias. Además, la quilca o "papel, carta o escritura" formada por signos pictográficos pintados a manos o incididos en alguna superficie. Finalmente, los tocapus, representaciones gráficas que se encontraban en los vestidos de la realeza y nobleza inca en forma de bordados o pintados en los keros, que serían un tipo de escritura basado en 400 signos. En cambio, el poquen cancha debió ser un medio para enseñar a partir de imágenes.

Unido a la fundación del yachayhuasi en el Cuzco, el soberano Inca Roca también fundó el primer acllahuasi o "casa de las escogidas", institución que impartía educación a las jóvenes mujeres que no necesariamente tenían que ser de la nobleza (de sangre y de privilegio) sino, también aquellas mujeres de las comunidades, ayllus y familias, que en forma de tributo eran entregadas al Estado inca. El formar parte del acllahuasi, era una oportunidad importante para una mujer 
que provenía de las clases sociales inferiores (pueblo); pues le permitía moverse de un grupo social inferior a uno superior, además que se aseguraba el sustento, y la posibilidad de desempeñarse en un oficio, al cual nunca iba poder acceder en su comunidad o ayllu, para finalmente ponerlo al servicio del Estado. Aunque las niñas eran ya seleccionadas desde los 4 años de edad, su ingreso oficial al acllahuasi se daba al promediar los 10 años de edad. ${ }^{6}$ Cuando libremente elegían seguir su educación. La educación en el Acllahuasi comprendía aproximadamente seis años, entre los cuales las acllas eran instruidas por mujeres adultas y con mucha experiencias denominadas mamaconas o "matronas" las cuales mediante el ejemplo y la explicación oral enseñaban a las mujeres jóvenes.

Concluida su formación, las acllas eran clasificadas para los servicios que iban a realizar para el Estado inca, esta selección era realizada tanto por el soberano como por el huillachumo, o "Sumo sacerdote"; al final podían ser: acllas del inca, las cuales estaban bajo la subordinación del inca para cualquier finalidad política o, acllas del sol, que eran las entregadas para los diversos oficios del culto. A estas últimas se las ha denominado "vírgenes del sol".

Se dieron en el incanato los elementos educativos esquematizados dentro de una concepción contemporánea del proceso. Esta educación fue eminentemente técnica en el pueblo, técnica y humanista en la nobleza con el fin de beneficiar al Estado en el aspecto económico y de preparar a los nobles para el gobierno. Existió por tanto, un sistema de enseñanza aprendizaje que estuvo basado en la intuición y bajo el control del Estado. De primera intención, descubrimos algunos elementos tipificantes de la educación: el educador, los procedimientos educativos y las instituciones correspondientes. El educador masculino está representado por el amauta, cuya variante en el arte es el haravicu y la educadora llamada mamacona. No hubo sistema educativo formal, pero sí empíricamente, se aplicó un conjunto de técnicas y procedimientos educativos que integrados corresponden a un sistema de enseñanza. El sistema y los procedimientos de enseñanza que se apreciaron en la educación del pueblo están dentro del nivel de índole familiar y comunal. Esta educación responde a dos características: Una educación familiar vinculada a la edad y una educación comunal vinculada con el Estado.

\section{La educación en el virreinato}

Desde los orígenes de la fundación española de nuevas ciudades, la población criolla sintió la necesidad de crear en la sociedad virreinal peruana las instituciones peninsulares. En los primeros años de la conquista, muchos de los españoles que venían a América lo hacían con el deseo de enriquecerse y volver a España mejorando su situación, pero muchos otros, que habían ganado aquí tierras y posesiones, empezaron a sentir la tierra como propia y junto con ello la necesidad de construir una ciudad al estilo de las europeas, incluyendo todos los servicios que podían ofrecer. Solo diez y seis años después de la fundación de Lima se abre la universidad, y después, todas las instituciones educativas existentes en la España de entonces.

Las instituciones educativas de la época son: las escuelas de primeras letras, que corresponden a lo que es hoy la escuela primaria. Las aulas de latinidad y los colegios de primeras letras en los que se aprendían latín y sería comparable a lo que actualmente es la secundaria Hemos de tener en cuenta que el aprendizaje del latín era indispensable para el ingreso a la universidad, donde todas las clases se dictaban en esta lengua. Los colegios de humanidades, fundados por los jesuitas, frecuentemente tienen incorporado estudios universitarios de filosofía y teología $\mathrm{El}$ tercer nivel, el universitario, es el más amplio. En primer lugar está la universidad, y junto a esta nacieron en el siglo XVI una serie de colegios de nivel superior que tuvieron distintas funciones: el colegio mayor de San Felipe y San Marcos y el seminario de Santo Toribio. En el S. XVII

' Basándose en Garcilaso, Rostworoswki propone entre 8 a 10 años; mientras que Gózales propone entre 12 a 13 años de edad. 
los colegios universitarios de religiosos de $\mathrm{S}$. Buenaventura de Guadalupe, de S. Pedro Nolasco, de Santo Tomás y de San Ildefonso. Por último en el S. XVIII el célebre Convictorio de San Carlos.

El contenido de esa educación abarcaba, además de los propios de la religión cristiana, la lectura, la escritura, el cálculo y, también en ocasiones, enseñanzas profesionales que fueran de gran utilidad al indio en su vida diaria y laboral. Existieron algunos colegios donde también los religiosos impartieron estudios superiores, destinados a la educación de los jóvenes hijos de caciques o de la alta nobleza, principalmente, ya que eran los destinados a ocupar los puestos más importantes dentro de la sociedad colonial, y porque con sus actuaciones constituían un ejemplo con respecto al resto de la población. Junto a esta labor evangelizadora, los misioneros desarrollaron una importante labor educativa y civilizadora. Acciones que llevaron a cabo de una manera conjunta y paralela, aunque siempre los principios de la doctrina cristiana eran los que marcaban su marcha, dada la trascendencia que tenía la fe cristiana en la sociedad española del Renacimiento, Barroco e Ilustración.

Estas acciones educativas y evangelizadoras permitían una mejora de los usos, prácticas y costumbres de los indios, y por lo tanto, de su civilización, a través de una modelación de su persona lo más parecida posible a la española, pero respetando la autóctona. Autoridades civiles y eclesiásticas se preocuparon por el cuidado, la promoción, educación, civilización y evangelización del indio. En el primer caso, un ejemplo de ello será la labor desarrollada por el virrey Toledo en el Perú, quien, como autoridad en un cargo político importante y como gran conocedor del territorio peruano por el número de visitas que realizó por distintos lugares, elaboró unas ordenanzas que regulaban la vida cívica y laboral del indio, con la finalidad de que no se cometieran agravios en su contra y que se potenciara sus habilidades y educación.

En el caso de personalidades eclesiásticas, Santo Toribio de Mogrovejo y José de
Acosta fueron quienes ocupan un lugar preeminente en la educación, humanización y evangelización de los indígenas. Ambos se preocuparon por conocer la realidad en la que vivían los naturales en el Perú, así como por adoptar las medidas que potenciaran sus capacidades y habilidades intelectuales.

El denominado "Plinio de América" -José de Acosta- fue una de las personas que más se interesó por la buena educación, cristianización y humanización de los naturales. A través de las visitas que realizó por el virreinato, observó por una parte que eran varios los errores cometidos por religiosos y civiles especialmente en la aplicación de una evangelización no siempre acertada; y por otra, que su mal ejemplo afectaba sobremanera el comportamiento de los indios y su buena predisposición para la recepción del evangelio y su participación en otras actividades educativas. Así, decidió reflexionar sobre qué medidas favorecerían el desarrollo educativo de los indígenas, con la finalidad de que permitieran el mayor éxito en las labores de enseñanza llevadas a cabo por los misioneros. Su aportación incluye la aplicación de importantes métodos educativos que se caracterizan por una capacidad de persuasión, por una actitud de perseverancia, así como por una comprensión de la cultura indígena y por un aprendizaje de la lengua quechua. Todas ellos planteados con el objetivo de conseguir una mayor efectividad en las labores de educación y evangelización. Además, tuvo un papel fundamental en la elaboración castellana del catecismo compuesto en el Tercer Concilio limense, así como en la aprobación de las medidas adoptadas en el mismo, ante el rey y el papa.

En el marco del proceso evolutivo de la educación institucional peruana, debe mencionarse la creación de un organismo destinado a coordinar, impulsar y liderar la educación de todos los peruanos. El 4 de febrero de 1837, en tiempos de fervor caudillista y agitación republicana de un país que surge a la vida independiente, don Andrés de Santa Cruz, Gran Mariscal Pacificador del Perú, decide crear un ministerio con el título de Ministerio de Instrucción Pública, Beneficencia y Negocios Eclesiásticos que 
nace orgullosamente con solo tres empleados. Al día siguiente, la planilla se incrementó con el nombramiento del primer ministro del sector, el presbítero doctor Manuel Gaspar de Villarán y Loli.

Al promediar el siglo XIX, el General Castilla promulga el primer Reglamento de Educación, que establece la separación entre educación pública y privada, al mismo tiempo que el colegio Guadalupe es declarado Colegio Nacional y se establece el profesorado como carrera pública. Durante los sucesivos gobiernos, la legislación del sector educación pasa por continuas metamorfosis como la sufrida en 1907, durante el Gobierno de Pardo y Barreda, y el establecimiento de la Instrucción Secundaria en cinco años. En 1935, Justicia y Culto se desligan del Ministerio de Educación, hasta llegar a ensayar en la década de los años 70 un complejo y ambicioso proyecto de reforma, en el que destaca el gran impulso a la Educación Inicial, acompañado - a partir de los años 80- con un fuerte desarrollo de la Educación Superior.

De 1980 a 1985, en el segundo Gobierno de Belaúnde Terry, se establece el llamado quinquenio de la educación. A partir de 1990, se da una nueva Ley del Profesorado y su Reglamento. En 1992, se transfiere el Instituto Nacional de Infraestructura Educativa (INIED) al Ministerio de la Presidencia. Se promulga la nueva Ley Orgánica del Ministerio de Educación, la Ley de Participación Comunal en la Gestión y Administración Educativa, y la Ley de Mejoramiento de la Calidad y Ampliación de la Cobertura de la Educación Peruana. En 1993, se promulga un nuevo reglamento de Organización y Funciones del Ministerio, y se hace efectiva la racionalización con el cese de trabajadores del sector, por reorganización. A partir de entonces, la educación peruana ha experimentado grandes cambios y enormes progresos en cuanto a infraestructura y calidad, aunque todavía es mucho lo que queda por avanzar.

En la dilatada trayectoria debe mencionarse en el año 2003 la Ley General de Educación (N. ${ }^{\circ}$ 28044) que establece "los lineamientos generales de la educación y del Sistema
Educativo Peruano, las atribuciones y obligaciones del Estado y los derechos y responsabilidades de las personas y la sociedad en su función educadora. Rige todas las actividades educativas realizadas dentro del territorio nacional, desarrolladas por personas naturales o jurídicas, públicas o privadas, nacionales o extranjeras". Deja claro que la educación es un derecho, la gratuidad, la libertad de enseñanza, la necesidad de formación ética y cívica, el Proyecto Educativo Nacional y la declaración principios fundamentales como el constituir "a la persona como centro y agente fundamental del proceso educativo" (Ministerio, 2003), la educación en valores: "paz, solidaridad, justicia, libertad, honestidad, tolerancia, responsabilidad, trabajo, verdad y pleno respeto a las normas de convivencia; que fortalece la conciencia moral individual y hace posible una sociedad basada en el ejercicio permanente de la responsabilidad ciudadana". Todo ello en equidad, calidad, democracia, interculturalidad.

\section{EL PERÚ, UN DESAFío ESPERANZADO}

El periodista Abelardo Gamarra, El Tunante, a fuer de ser realista en el marco auroral del Perú naciente entre dolores de parto, parece olvidar los dos esperanzadores apartados anteriores del Perú, y sentencia escéptico: "En esta tierra (del Perú) se podría colgar el cartel que puso Dante en el infierno: dejad toda esperanza los que entráis en él". (Alarcón, 2007)

Dicen que lo dijo el naturalista Antonio Raimondi, aunque nadie lo demuestra pero se sigue repitiendo como maléfica letanía, al hacer un recorrido por todo el país en el siglo XIX y comprobar sus potenciales riquezas rodeadas por una extremada pobreza: «El Perú es un mendigo sentado en un banco de oro».

Lo que sí es cierto que, poco antes de su muerte en San Pedro de Lloc, en 1890, pronunció como testamento:

Jóvenes peruanos, confiado en mi entusiasmo emprendí un arduo trabajo muy superior a mis fuerzas; os pido, pues, 
vuestro concurso. Ayudadme, dad tregua a la politica y consagraos a hacer conocer vuestro país y los inmensos recursos que tiene. Os dejo todavía un vasto campo en que ejercitar la investigación; la senda para que vosotros, continuando los estudios, saquéis a la luz los inmensos caudales que yacen ocultos en vuestro suelo nativo. (Bernex, 1995, p. 125)

¿A qué esperamos? El gran César Vallejo nos lo recuerda también: "iHermanos, hay mucho que hacer!". Son numerosos los proyectos que se han puesto en marcha y que cuentan con la aprobación mediática como el premio de "Integración y solidaridad" de RPP que estimula precisamente iniciativas educativas en bien de la comunidad. No se puede olvidar la benéfica acción de los colegios "Fe y Alegría" que -allí donde termina el asfalto- cuenta en la actualidad con más de 88.000 niños y jóvenes en sus 80 instituciones educativas a lo largo de 20 departamentos del Perú.

Cito un buen ejemplo de lo que se ha hecho y se puede hacer. En solo cinco años, un caótico y anónimo arenal se convirtió en una moderna Plaza Mayor, cuyo corazón lo constituye una catedral armónica y con personalidad bien definida. No se había creado una catedral desde el terremoto de 1970, que asoló Ancash y que generó el derrumbe del nevado Huascarán y la desaparición del pueblo de Yungay. Miles de brazos, millones de dólares, miles de piedras, miles de bolsas de cemento, miles de kilos de fierro, en torno al Don Bosco de Chacas, el educador salesiano Hugo de Censi, quien con su Operación Matto Grosso y su fe en Dios, ha logrado del Cielo este milagro.

Más sublime que levantar una catedral es forjar hombres, labrar personas, formar maestros de maestros. Urge como nunca conocer la historia de esta hermosa realidad, sin ir fuera, en nuestra propia identidad, sin desconocer la globalidad, pero desde la peruanidad. Nuestro compromiso académico inmediato es nuestra realidad, por ello hay que estudiar la trayectoria educativa del Perú a través de sus leyes, instituciones, personas y su influjo en la sociedad.
El historiador y educador Gustavo Pons Muzzo nos invita a transitar por el Perú, camino, tesoro, desafío, a través de un proyecto educativo nacional que ilusione corporativamente a todos peruanos:

Una educación verdadera cumple funciones de conservación, rectificación y superación social y cultural. Asegura la unidad y la renovación espiritual de los pueblos. Educación es arraigo de valores vigentes y generación de otros nuevos. El sistema educativo de nuestro pueblo debe desenvolverse en función de la vida nacional y de la cultura universal a que pertenecemos. La vida nacional tiene por base una realidad cultural propia. Nuestra cultura es producto de la transculturación de la cultura indígena surgida aquí hace miles de años y la cultura occidental traída por España a partir del siglo XVI (1953, pp. 29-31)

Para lograrlo se necesita dar protagonismo $e$ incorporar a los jóvenes peruanos al Perú vital, múltiple y total, formando su personalidad de acuerdo con los valores esenciales de la peruanidad. Tales ideales y paradigmas deben fijarse de acuerdo con el patrimonio cultural heredado, abiertos a la realidad global del momento y esperanzados en lograr un desarrollo integral para todo el Perú y todos los peruanos. Perú necesita maestros inasequibles al desaliento y eternos recomenzadores llenos de esperanza.

La simpática acuarela de Pancho Fierro sobre el maestro de escuela nos da la perspectiva de "pasión", de "riesgo" y "gozo" que la educación contiene. En este momento en que el Gobierno Peruano quiere dar solución a la declaratoria de emergencia educativa ante los pésimos resultados (penúltimos de América) en lectura, matemáticas y formación en valores, todos debemos comprometernos a ver la realidad y a adoptar una postura positiva y esperanzadora a pesar de la situación crítica de la educación en Perú.

De los 30 millones de peruanos, unos quince millones son jóvenes. De ellos saldrán los 
protagonistas de la Humanidad de nuestro contexto. Debemos reflexionar acerca de su situación, de sus valores, sus actitudes, para potenciar sus grandes energías. Todo ello, sin desconocer los grandes problemas de cientos de pandillas en las que naufragan miles de jóvenes a la deriva. Otra de las claves de los jóvenes actuales nos da el denominado síndrome de Peter Pan, esto es, la negativa a crecer, tal como le sucedió al héroe de Barrie. Los valores percibidos por los jóvenes como fundamentales son: la autonomía (fundante de lo bueno y de lo malo), el pluralismo tolerante ("que no me molesten") y relativista (sin verdades absolutas), el presentismo (vivir a tope el ahora, sin planificar nada excepto el fin de semana y hasta que el cuerpo aguante), la concepción utilitarista del trabajo y la disociación entre fines y medios. iCuántos jóvenes luchan por la excelencia académica, por el triunfo profesional, dejando a un lado su formación moral! Los mismos centros educativos, no ponen quizá tanto empeño en la conciencia como en la ciencia y la técnica. Todo esto lleva a otra clave identificada por el sociólogo de la Universidad de Deusto, Javier Elzo Imaz, "el aburrimiento". (1998)

Cuenta el mito de la Grecia clásica que Minotauro era un monstruo con cabeza de toro y cuerpo humano, fruto de los amores de Pasífae y un toro blanco, al que el rey Minos encerró en un laberinto donde todos quedaban atrapados sin poder salir. Fue el héroe ateniense, Teseo, quien logró matarlo y hallar la salida gracias al ovillo de Ariadna, hija de Minos y Pasifae. Nuestro mundo, como nuevo Teseo, busca salir del laberinto pasional y la ofuscación ideológica que la postmodernidad le ha tejido.

Uno de los educadores que ha propuesto un plan de educación nacional, Gustavo Pons Muzzo (1953), nos lanza provisionalmente los siguientes principios básicos:

- El ideal de la integración nacional, con los incas, en la época virreinal, y durante la República.

- Educar para la adaptación social, incorporando al joven peruano a la vida actual, con sus problemas, angustias y posibilidades.

- Educando para la eficiencia personal para ayudar al progreso del país y al bienestar personal de sus ciudadanos.

- Educar para una efectiva actividad

religiosa que le haga sentir sus preceptos católicos como normas morales de acción en la vida ciudadana.

- Educar para la solidaridad continental que busque la paz y la armonía entre los pueblos. La educación nacional no puede olvidar la sangrante y dolorosa historia internacional del Perú, que por creer que ese sentimiento americanista y de solidaridad continental era participado por todos, sufrió amargas amputaciones territoriales que lesionaron las entrañas mismas de la nacionalidad. Vamos a educar a nuestra juventud en un sentimiento de solidaridad continental, pero también con un sentido de ALERTA frente a los demás países americanos y en especial frente nuestros vecinos.

Vemos que en buena medida se recogen en el artículo N..$^{\circ} 9^{\circ}$ de la Ley General de Educación 28044 como "Fines de la educación peruana":

a) Formar personas capaces de lograr su realización ética, intelectual, artística, cultural, afectiva, física, espiritual y religiosa, promoviendo la formación y consolidación de su identidad y autoestima y su integración adecuada y crítica a la sociedad para el ejercicio de su ciudadanía en armonía con su entorno, así como el desarrollo de sus capacidades y habilidades para vincular su vida con el mundo del trabajo y para afrontar los incesantes cambios en la sociedad y el conocimiento.

b Contribuir a una sociedad democrática, solidaria, justa, inclusiva, próspera, tolerante y forjadora de una cultura de paz que afirme la identidad nacional sustentada en la diversidad cultural, étnica y lingüística, supere la pobreza e impulse el desarrollo 
sostenible del país y fomente la integración latinoamericana teniendo en cuenta los retos de un mundo globalizado.

\section{PERÚ, LA HORA DEL AHORA}

El aquí y el ahora del Perú requieren marcar la hora del responsable, del formador, del líder, del maestro, la hora del que vive lo que enseña y enseña lo que vive. "La hora del maestro" para J. Ortega y Gasset debe pasar "en lo intelectual por la curiosidad y el ansia por superar constantemente el propio horizonte; en lo cordial la nobleza". Tal fue el aserto del maestro de la historia republicana del Perú, Jorge Basadre, en su escrito a la UNEC en 1946: "Chesterton ha dicho: "Yo no sabía lo que entendía por libertad hasta que la oí designar con el nuevo nombre de Dignidad Humana: Más que nunca en este instante del mundo es preciso construirse por dentro como una voluntad y como una aspiración de Dignidad" (Benito, 2009) Veinte años después, dirá que "lo que realmente importa, en la vida y en la obra, es ser uno leal consigo mismo, proceder de acuerdo con el fondo insobornable' que todos llevamos dentro" (Basadre, 1966, p. 48) En 1997 secumplió el centenario del nacimiento de uno de los más ilustres universitarios del Perú: Raúl Porras Barrenechea. Historiador, literato, político, pero también, y sobre todo, maestro. La revista Caretas de 13 de marzo de aquel año nos recordaba el propio testimonio recogido de los discípulos de Porras: "No puede haber, no hay a mi juicio mayor placer ni mayor honra espiritual que ser maestro". Nosotros podríamos añadir salvo el del discípulo que se encuentra con un auténtico maestro.

La escuela, el colegio, la universidad han girado y gira en torno a los maestros. Viven lo que enseñan y enseñan lo que viven. No es el método ni la técnica quienes hacen bueno al maestro sino al revés: el buen maestro categoriza, eleva, ennoblece los métodos. Entre los maestros del Perú, cabe mencionar al Deán Valdivia, primer director del Colegio Independencia y primer rector electo de la UNSA (Universidad Nacional San Agustín) de Arequipa, quien incursionó de forma enciclopédica en casi todas las ramas del saber (medicina, derecho, filosofía, teología, química, historia...). En el Doctor Valdivia todo es sabiduría de maestro universitario; su afán por buscar la verdad, su celo por comunicarla, su pasión por convertirla en útil sillar del cimiento de la justa y solidaria sociedad que anhela construir. Se dio del todo a través de sus libros, tratados, artículos y, sobre todo, de sus discípulos. Del maestro de los filósofos por antonomasia, Sócrates, que como se sabe no escribió ningún libro, se llegó a decir que sus mejores obras fueron sus discípulos; ahí está Platón para asegurarlo. De nuestro citado maestro, Juan Gualberto Valdivia, no he encontrado mejor reconocimiento que el formulado por uno de los más destacados historiadores arequipeños, Francisco Mostajo:

Pedagogo de sí mismo, fuélo también de la juventud confiada a su cuidado, y para diademar su nombre de maestro bastan los de algunos de sus más esclarecidos discípulos: Manuel Toribio Ureta, José Ciriaco Hurtado, José María Químper, José Simeón Tejada y Francisco García Calderón. (UNSA, 1953, p. 228)

Claro que esta relación estrecha entre el alumno y el maestro no se improvisan. Requiere una dedicación mutua, limpia y desinteresada. Lo mismo que la auténtica paternidad o maternidad no se reduce a la vinculación carnal, sino que se cultiva con el trato, la aceptación, el afecto..., el título de maestro se consigue por la autoridad profesional y moral, así como el de discípulo se gana por la docilidad creativa. El mayor gozo del maestro es descubrir un discípulo, potenciándolo al máximo de sus posibilidades, logrando que le supere. Es lo que manifiesta nuestro célebre Deán en la dedicatoria de Las revoluciones de Arequipa (Arequipa, 1874) con F. García Calderón, futuro presidente del Perú:

El cariño que te profeso desde tu niñez, y la gratitud y estimación que me has demostrado siempre por el cuidado que he tenido de tu educación, te hacen acreedor a que yo te dedique este trabajo. Acéptalo como una pequeña ofrenda de mi puro afecto hacia ti y de la ternura de padre y amigo agradecido con 
que te recuerda siempre, tu VALDIVIA" (Valdivia, 1956, p. 3)

Cariño, gratitud, ternura. Palabras definitivas para esculpir, forjar los maestros del siglo XXI que quiere $y$ requiere el Perú.

Recientemente se celebró el centenario del nacimiento de un gran educador peruano, José María Arguedas, mentor de una patria de "todas las sangres". Recordar su trayectoria nos ayudará a comprometernos con el Perú total que tan hondamente vivió y describió. Nace en el Perú profundo de Andahuaylas en 1911 y muere en Lima en 1969. Aprendió la lengua quechua al relacionarse con niños indígenas y se adaptó a sus costumbres. En los viajes que realiza con su padre (Mollendo, Arequipa y Cusco) se familiariza aún más con la problemática andina. Estudió la secundaria en Ica, Huancayo y Lima; en los colegio San Luis Gonzaga, Santa Isabel y Mercedarios, respectivamente. Estudia como alumno libre sus dos últimos años. Ingresa a la universidad de San Marcos en 1931, cuando tenía veinte años. En tal casa de estudios sigue las especialidades de Literatura y Antropología. Graduado como doctor en antropología en 1963, fue profesor de esas disciplinas en la Universidad Nacional Mayor de San Marcos y en la Universidad Agraria hasta su fallecimiento. El zorro de arriba y el zorro de abajo (1971) fue publicado de forma póstuma. En esta última obra Arguedas combina la ficción con otros personajes en los que se percibe la situación depresiva en la que se encontraba el escritor. Con esta inconclusa novela, Arguedas se despide del mundo, registra sus últimos días de vida y anticipa su suicidio. El médico Santiago Stucchi Portocarrero al concluir el análisis de su depresión señala que su muerte "fue el trágico final de un hombre atormentado por la depresión". El P. Gustavo Gutiérrez, confidente de Arguedas, dirá de él que "es el escritor de los encuentros y desencuentros de todas las razas, de todas las lenguas y de todas las patrias del Perú. Pero no es un testigo pasivo, no se limita a fotografiar y a describir, toma partido." (Benaloy, 2011, p. 285) Como lo tomó un maestro de primaria, Alejandro Cussiánovich, quien fundó el Movimiento de
Adolescentes y Niños Trabajadores y siembra a manos llenas ante la emergencia educativa que sacude a nuestra patria la "pedagogía de la ternura", entre los chicos que trabajan.

Y como lo tomó una alumna de 103 años, Antonia Paz Álvarez, quien logró aprender a leer y escribir en el círculo "Caritas Pintadas", instalado por el Programa Nacional de Movilización por la Alfabetización (PRONAMA), en el distrito de Majes, provincia de Caylloma, región Arequipa. Con el apoyo de sus vecinas y compañeras del citado círculo de alfabetización, así como de su facilitador, Manuel Febres, la dama arequipeña empezó con los ejercicios necesarios para poder habilitar su mano derecha al movimiento propio de una escritura. Esta etapa no le fue complicada toda vez que Antonia Paz estaba acostumbrada al trabajo propio del campo y del tejido, que requieren una gran habilidad de las manos y brazos. Ella representa la síntesis viviente de la peruanidad, el arrojo y el temple de la mujer peruana, el ideal de superación, el entusiasmo de ser más, de superarse. Ella, alumna de primeras letras, se convierte en una maestra llena de vida.

Carlos Cueto Fernandini_(1913-1968) nos lo legó como patrimonio y como paradigma:

Es maestro TODO AQUEL que se siente capaz de trabajar empeñosamente al servicio de un ideal, sin guardar para sí los frutos de su trabajo; TODO AQUEL que al conversar con otro, siente el placer de beneficiar con su pensamiento a aquel con quien dialoga y de escuchar atentamente el mensaje que puede desprenderse de las palabras recogidas; TODO AQUEL que apetezca sumergirse, en los valores que empujen a los demás en la práctica del bien; TODO AQUEL que se reconozca a sí mismo en las justas aspiraciones de un hombre cualquiera, aun cuando ese hombre no sea su amigo, y a pesar de que esa aspiración no compromete ninguno de sus intereses personales. TODO AQUEL que se sienta enriquecido cuando da; TODO AQUEL que sabiendo, olvida que sabe; TODO AQUEL que se sienta capaz de trabajar 
por los demás; sin extender enseguida la mano para demandar la recompensa; TODO AQUEL que crea firmemente que el destino del hombre puede ser siempre mejor; TODO AQUEL que quiere hacer de los demás hombres maestros como él; Si lo es de veras, cualquier ser humano puede ser un MAESTRO. (Cueto)

Concluyo como lo hace el joven graduado de la PUCP, José Armando Talavera Montes, ganador en el 2014 del premio promovido por El Comercio en el rubro "educación". Tras su lúcido y esperanzador análisis, insta a todos los actores del proceso educativo a llegar al 2021 con una Educación "no como problema, sino como herramienta y oportunidad de desarrollo... con la perspectiva de ser un país ad portas del desarrollo y con futuro", en el que acometan dos tareas fundamentales: el desarrollo de las capacidades de todos los peruanos y la formación de una ciudadanía inclusiva". ${ }^{7}$

Mi deseo para el Perú, por tanto, al subirnos al "tren" del bicentenario de su independencia en el 2021 que viene, es invitar a caminar juntos - sinodalmente $e^{8}$, tras las huellas de su legado patrimonial cultural y educativo, para construir un Perú total, globalizado e inclusivo, justo y solidario, fiel a sus raíces pero abierto a los desafíos de los nuevos tiempos, que valore siempre su más preciado tesoro: su gente y el gozoso riesgo de educar.

Fecha de recepción: 15 de mayo 2015

Fecha de aceptación: 19 de junio 2015

7 Talavera Montes, José Armando "Educación como libertad" http://3.elcomercio.e3.pe/doc/0/0/8/8/1/881627.pdf

8 Etimológicamente "sínodo" significa "caminar todos a una". 


\section{REFERENCIAS}

Abbagnano, N. y Visalberhi, A. (1990) Historia de la Pedagogía. México: Editorial FCE.

Acosta, José de (1984 [1588]) De Procuranda Indorum Salute (Pacificación y Colonización). Madrid, CSIC.

Acosta, José de (1954 [1590]) Historia natural y moral de las Indias. BAE, 73. Madrid: Atlas.

Alaperrine-Bouyer, Monique (2007) La educación de las élites indígenas en el Perú colonial Lima: IFEA-IRA.

Alarcón, Alberto (2007) "Lo que el Tunante dijo ayer" http://papelesdeproteo.blogspot. com/2007/07/lo-que-el-tunante-dijo-ayer.html

Alvarez Cantorín, Luz Mery (2003) ENCINAS, JOSE ANTONIO, 1888-1958 Grandes Educadores Peruanos Ministerio de Educación, Lima, EDUCADORES / BIOGRAFIAS /. PERU. 378.199

Arista M. G. (2007) Educación peruana. Material de estudio. Lima: Facultad de Teología Pontificia y Civil de Lima.

Avanzini, G. (1977) La pedagogía en el siglo XX. Madrid: Narcea.

Ayala, A (1946) Formación de selectos. Madrid: Atenas.

Ayuso Manso, María Jesús. (2006) "Educación y escuela en los tiempos de Cervantes" El Riesgo de Educar 88-96, año 1, N. ${ }^{\circ}$ 2, Lima: UCSS.

Barrantes, Emilio (1989); Historia de la Educación en el Perú. Lima: Mosca Azul.

Barriga Hernández, C.y Palacios Navarro, G. (1998) Historia de laEducación (Texto autoinstructivo). Lima: Facultad de Educación, UNMSM, $2^{a}$ ed.

Basadre, Jorge. (1996) Perú Vivo. Lima: Juan Mejía Baca.

Belaunde, Víctor A. (1993 [1942]) La peruanidad integral: Discurso en las bodas de plata de la U. Católica, "Palabras de Fe" en Obras Completas Lima: Pontificia Universidad Católica del Perú / Instituto Riva-Agüero.

Benaloy, Jaume (2011) "Los zorros", Arguedas y el Padre Camacho en Chimbote Increscendo, Revista Científica de la Universidad Católica Los Ángeles de Chimbote. Vol. $2 \mathrm{~N}^{\circ} 2$, julio-diciembre, 285-293.

Benito Rodríguez J. A. (1991) "La promoción humana y social del indio en los concilios y sínodos de Santo Toribio" Actas del IV Congreso Nacional de Americanistas "Castilla en América" (Caja España, Valladolid, t. III, 279-294.

Benito Rodríguez J. A. (1993) "Nuestro Nuevo Mundo (Experiencia)" Primeras Noticias octubre Barcelona, 21-24.

Benito Rodríguez J. A. (1995) Toribio Mogrovejo: El castellanoleonés que abrazó todas las razas Junta de Castilla y León, Valladolid. 
Benito Rodríguez J. A. (1996) "La vocación pedagógica del Deán Valdivia”, El Comercio 15-VII-96, 3.

Benito Rodríguez J. A. (2000) "Santo Toribio: Pionero de la educación" Revista pedagógica Maestros Lima, N. . $13,87-90$.

Benito Rodríguez J. A. (2005) "Un educador para los pueblos jóvenes de Arequipa" Revista Pedagógica Maestros N. ${ }^{\circ}$ 25-26, Vol.11, 95-98.

Benito Rodríguez J. A. (2005) "Un vallisoletano ilustrado en el Perú: El prelado Manuel Abad Yllana (1713-1780)" Luces y reformas en el Perú del siglo XVIII. Cuadernos de Humanidades, Universidad de Piura, 25-104.

Benito Rodríguez J. A. (2006) "Educador y descubridor, Cristóbal Colón" Revista Riesgo de educar Lima: Universidad Católica "Sedes Sapientiae", año 1, N. ${ }^{\circ}$ 1, 45-51.

Benito Rodríguez J. A. (2006) "Hernando de Guzmán, Rector de la Universidad de San Marcos y del Seminario de Santo Toribio (1568-1638)". UKU PACHA Lima: Revista de Investigaciones Históricas Año 5. N. ${ }^{\circ}$ 9, Julio, 71-77.

Benito, José Antonio (2009) "Maestros en Perú" http:/jabenito.blogspot.com/2009/07/maestrosen-peru_04.html

Bernex De Falen, N. (1995) Antonio Raimondi. Lima: Editorial Brasa.

Borghesi, M. (2007) El sujeto ausente, Encuentro-UCSS, Lima.

Calero Pérez, M. (1999) Historia de la Educación Peruana. Lima: Editorial San Marcos.

Cardó Franco, Andrés (2005) La iglesia y la educación en el Perú.2a.ed. Arequipa: Universidad Católica San Pablo, 2005.

Chocano, J. S. "Poemas de José Santos Chocano" http://www.diarioinca.com/2008/03/poemasde-jose-santos-chocano.html

Chico González, P. (2000) Institutos y fundadores de educación cristiana, La Salle, Valladolid, 7 vols. (www.lasalle.es/catequesis2).

Cueto Fernandini, Carlos (2003) Grandes educadores peruanos. Lima: Carlos Milla Batres, (ed.).

Corazao, Julio (1990) Valores Lima: Bruño.

Delors, J. (1996) La educación encierra un tesoro Madrid: Santillana.

Delgado Santagadea, K. (1992) "Reformas educativas en el Perú republicano" Hacia una nueva historia de la educación peruana, Lima.

Derrama Magisterial (s. f.) Colección pensamiento educativo http://www.derrama.org.pe/principal/ categoria/coleccion-pensamiento-educativo-peruano/291/c-291

Elzo Imaz, Javier (1998) http://www.alfayomega.es/Revista/1998/136/01_enportada1.php

Encinas, J. A. ([1932], 1986) Un ensayo de escuela nueva en el Perú Lima: CIDE. 
Gaceta del Gobierno, N. ${ }^{\circ} 22$, tomo 7 del jueves 10 de marzo de 1825.

Gerbi, Antonello (1944) Caminos del Perú Lima: Banco de Crédito del Perú.

Giussani, L. (1991) Educar es un riesgo Encuentro, Madrid. (2ª ed.)

Glave, L. M. (1999) "Caminos de Peregrinos” en Perú-El Dorado, Lima: PromPeú, N. o? 16, julioseptiembre. 64-72.

González Carré, Enrique (2004) Educación Prehispánica en el Perú Lima: IFEA.

González Carré, Enrique; Del Pino-Díaz, Fermín (2013) Aprender e instruir en los Andes, siglo XV-XVI. Lima: Derrama Magisterial. (Pensamiento educativo peruano, 1)

González y Galdo (1980) "Historia de la Educación en el Perú", pp. 11-123, Historia del Perú. Tomo X. Lima: Editorial Juan Mejía Baca.

Guerra Martiniére, Margarita y Leiva Viacava, Lourdes (2001) Historia de la educación peruana en la república: 1821-1876. Lima: Biblioteca Nacional del Perú. Fondo Editorial. 200 p.

Hyslop, John (1992) Qhapaqñan (El sistema vial inkaico), (Traductor Eduardo Arias). Lima: Instituto Andino de Estudios Arqueológicos, Petróleos del Perú.

Juan Pablo II (1985). Liturgia de la Palabra en Cuzco (Homilía del Santo Padre Juan Pablo II) http://w2.vatican.va/content/john-paul-ii/es/homilies/1985/documents/hf_jp-ii_hom_19850203_ cuzco.html

Leiva Viacava, Lourdes (2004) Aportes de Basadre a la educación peruana. Lima: UNIFE.

León Pinelo, Antonio de (1943 [1656]) El Paraíso en el Nuevo Mundo: comentario apologético, historia natural y peregrina de las Islas Occidentales, islas de Tierra firme (sic) del Mar Océano Ed. Raúl Porras Barrenechea, Lima: Torres Aguirre.

Marzal, Manuel M. (1991) La transformación religiosa peruana. Lima: PUCP.

Maticorena, M. (2000) Prioridad de la Universidad de San Marcos en América. Lima.

Ministerio de Educación Ley General de Educación (2003) http://www.sipi.siteal.org/ normativas/181/ley-ndeg-280442003-ley-general-de-educacion.

Ministerio de Educación "Reglamento de la Ley General de Educación N. o 28044" http://www. minedu.gob.pe/normatividad/reglamentos/EducacionCalidadyEquidad.pdf

Montalvo, F. A. de El Sol del Nuevo Mundo Lima 1683 https://archive.org/stream/ elsoldelnuevomun00mont/elsoldelnuevomun00mont_djvu.txt

Monsalve Zanatti, M. (1994) Historia de la Universidad de San Marcos y la Facultad de Teología (1551-1640), en Revista Teológica Limense Vol. XXVIII, 2-3, 288-331.

Mostajo, Francisco (1953) ("Homenaje al Dr. Francisco Mostajo"), "Homenaje a cinco Jurisconsultos: Corbacho, Martínez, Valdivia, Ureta y García Calderón". Revista_UNSA, Arequipa, N. ${ }^{\circ} 38$. 
Pajuelo, Marta (1982) Jorge Polar educador. Lima: BIRA, N. ${ }^{\circ}$ 12, 313-321.

Palma, Ricardo (1984) "iAl rincón! iQuita calzón!" en Tradiciones peruanas. t. II. Barcelona: Océano. 443-445.

Perú Ministerio de Educación (2003) Grandes educadores peruanos; libro dedicado a los maestros peruanos en su día. Lima: Carlos Milla Batres, 321.

Pons Muzzo, Gustavo (1953) Hacia una doctrina de la Educación Nacional. Lima: Imprenta Colegio Militar Leoncio Prado, Lima, 1953.

Pons Muzzo, Gustavo (1953) Educación para los jóvenes peruanos. Hacia una doctrina de la Educación Nacional. Lima: Imprenta Colegio Militar Leoncio Prado.

Rodríguez Cruz, Águeda M. (1992) La Universidad en la América Hispánica. Madrid: Colecciones Mapfre 1492.

Rojas Galarza, C. (1992) "La Educación en la República Aristocrática" Hacia una nueva historia de la educación peruana. Lima: Magisterio.

Soto Canales, P. (2007) "Agentes educativos en el Cuzco incaico". El Riesgo de Educar 88-96, año 2, N. ${ }^{\circ} 3,74-84$. Lima, año 2, N. $^{\circ} 3,88-96$,

Valcarcel, Carlos Daniel (1989) Historia de la Educación Peruana. Lima: Editorial Minerva.

Valdivia, Juan Gualberto (1956) Memorias sobre las revoluciones de Arequipa. Arequipa: El Deber.

Vargas Llosa, M. Discurso en la PUCP al recibir la condecoración como doctor honoris causa http://www.pucp.edu.pe/puntoedu/images/documentos/institucionales/sueno-realidad.pdf

Vargas Llosa, Mario (2010) "Elogio de la lectura y la ficción" (2010) http://es.scribd.com/ doc/44878069/Mario-Vargas-Llosa-Elegio-de-la-lectura-y-la-ficcion

Velázquez Mercado, Fr. M. (2006) "La Educación de la República en el Período 1821-1895. Estudio macroeducativo". Lima: La Merced, año IV, N. 7, 83-128,

Villegas, S. (agosto 2006) El descubrimiento de la infancia en el Perú. Percepciones en el proceso de la Colonia a la República Aristocrática Tiempos, en La Revista de historia y cultura, 45-72.

Wiesse, C. (1963) Establecimientos de enseñanza virreinal. Biblioteca de Cultura Peruana Contemporánea. Lima: Ediciones El Sol. 290-297, T. IV.

Whitman, Walt Poemas

http://www.whitmanarchive.org/published/foreign/spanish/vasseur/text.html

Manuscritos

Archivo Arzobispal de Lima (AAL). Papeles importantes.

AAL. AAL, Papeles Importantes, Legajo III. Expediente 12. Año1611.

AAL, Papeles Importantes III-14.

AAL, Papeles Importantes III-20.

AAL, Papeles Importantes III-21. 